Pacific Journal of

Mathematics

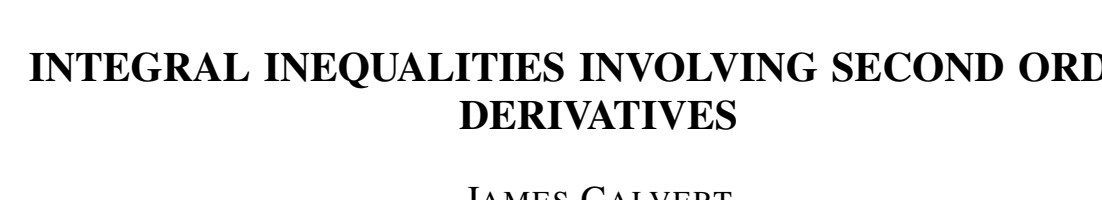




\title{
INTEGRAL INEQUALITIES INVOLVING SECOND ORDER DERIVATIVES
}

\author{
JAMes CALvert
}

An integral inequality involving second order derivatives is derived. A most important consequence of this inequality is that the Dirichlet form

$$
D(u, u)=\int_{D^{i, k}} a_{i k} D_{i}^{2} u D_{k}^{2} \bar{u}=q|u|^{2} d x \geqq 0,
$$

for functions $q(x)$ which are positive and "not too large" in a sense which will be made precise later and for functions $u(x)$ with compact support contained in $D$. Some examples are given and an application is made to an existence theorem for a fourth order uniformly elliptic P.D.E.

An earlier paper by the author [1] contains some similar results for inequalities involving first derivatives. The following definitions and notations will be used throughout the paper. Let

$$
x=\left(x_{1}, x_{2}, \cdots, x_{n}\right) \in R^{n} .
$$

Let $D$ be an open domain in $R^{n}$ which may be unbounded. Let $C^{\infty}(D)$ denote the set of infinitely differentiable complex valued functions on $D$ and let $C_{0}^{\infty}(D)$ denote the subset of $C^{\infty}(D)$ consisting of functions with compact support contained in $D$. Let

$$
\|u\|_{q}=\left(\int_{D} \sum_{i=1}^{n}\left|D_{i}^{2} u\right|^{2}+q|u|^{2} d x\right)^{1 / 2}, \text { where } D_{i}^{2} u=\frac{\partial^{2} u}{\partial x_{\imath}^{2}}
$$

and $q$ is either equal to 1 or to one of the positive functions to be defined later. Let $H_{q}(D)$ be the completion of $\left\{u \in C^{\infty}(D):\|u\|_{q}<\infty\right\}$ with respect to $\|u\|_{q}$ and let $\stackrel{\circ}{H}_{q}(D)$ be the completion of $C_{0}^{\infty}(D)$ with respect to $\|u\|_{q}$. The functions $u$ in $H_{q}(D)$ or $\stackrel{\circ}{H}_{q}(D)$ have strong $L_{2}$ second derivatives which we will denote by the same symbol as for the oridnary derivative. So that

$$
\lim _{n \rightarrow \infty} \int_{D}\left|D_{i}^{2} u-D_{i}^{2} u_{n}\right|^{2} d x=0
$$

where $\left\{u_{n}\right\}$ is any sequence of elements in $C^{\infty}(D)$ such that $\left\|u-u_{n}\right\|_{q} \rightarrow 0$. All coefficient functions considered will be real valued. The variable functions $u$ may be complex valued. There do not seem to be any analogues of the basic results with complex valued coefficients.

THEOREM 1. Suppose that the boundary of $D$ is smooth enough 
to apply Gauss' Theorem. Let $a_{i k} \in C^{1}(D)$ and $\left(a_{i k}\right)$ be symmetric positive definite. Let $f_{1}, f_{2}, \cdots, f_{n} \in C^{1}(D), q_{k}=\left(f_{k}+D_{k}\right) f_{k}$ and suppose that $\sum_{i} a_{i k} q_{i} \leqq 0$, for every $k=1,2, \cdots, n$. Then, for any $u \in C^{1}(D)$,

$$
\begin{aligned}
& \int_{D} \sum_{i, k} a_{i k} D_{i}^{2} u D_{k}^{2} \bar{u}-\left(f_{i}+D_{i}\right)^{2}\left(a_{i k} q_{k}\right)|u|^{2} d x \\
& \quad \geqq \int_{\dot{D}} \sum_{i, k}\left[a_{i k} q_{i} D_{k}|u|^{2}-\left(D_{k}\left(a_{i k} q_{i}\right)+2 a_{i k} q_{i} f_{k}\right)|u|^{2}\right] \nu_{k} d s
\end{aligned}
$$

where $\nu_{k}$ is the $k^{\text {th }}$ component of the normal and the integral on the integral on the right is assumed to exist. Equality holds if and only if $D_{i}^{2} u=q_{i} u$ and $D_{i} u=f_{i} u$, for every $i$.

Proof. We shall require two integrations by parts.

$$
\begin{aligned}
& \int_{D} a_{i k} q_{i}\left(u D_{k}^{2} \bar{u}+\bar{u} D_{k}^{2} u\right) d x \\
&=-\int_{D}\left[a_{i k} q_{i} D_{k} u+u D_{k}\left(a_{i k} q_{i}\right)\right] D_{k} \bar{u} \\
&+\left[a_{i k} q_{i} D_{k} \bar{u}+\bar{u} D_{k}\left(a_{i k} q_{i}\right)\right] D_{k} u d x \\
&+\int_{\dot{D}} a_{i k} q_{i}\left(\bar{u} D_{k} u+u D_{k} \bar{u}\right) \nu_{k} d s \\
&= \int_{D} D_{k}^{2}\left(a_{i k} q_{i}\right)|u|^{2}-2 a_{i k} q_{i}\left|D_{k} u\right|^{2} d x \\
&+\int_{\dot{D}}\left[a_{i k} q_{i} D_{k}|u|^{2}-D_{k}\left(a_{i k} q_{i}\right)|u|^{2}\right] \nu_{k} d s
\end{aligned}
$$

and

$$
\begin{aligned}
& -\int_{D} a_{i k} q_{i} f_{k}\left(\bar{u} D_{k} u+u D_{k} \bar{u}\right) d x \\
& =\int_{D} D_{k}\left(a_{i k} q_{i} f_{k}\right)|u|^{2} d x-\int_{D} a_{i k} q_{i} f_{k}|u|^{2} \nu_{k} d s . \\
& \sum_{i, k} a_{i k}\left(D_{i}^{2} u-q_{i} u\right)\left(D_{k}^{2} \bar{u}-q_{k} \bar{u}\right)-2 \sum_{i} a_{i k} q_{i} \sum_{k}\left|D_{k} u-f_{k} u\right|^{2} \geqq 0 \\
& \quad \int_{D} \sum_{i, k} a_{i k} D_{i}^{2} u D_{k}^{2} \bar{u}-\left(f_{i}+D_{i}\right)^{2} a_{i k} q_{k}|u|^{2} d x \\
& \geqq \int_{D} \sum_{i, k}-\left(f_{i}+D_{i}\right)^{2} a_{i k} q_{k}|u|^{2}+a_{i k} q_{i}\left(u D_{k}^{2} \bar{u}+\bar{u} D_{k}^{2} u\right)-a_{i k} q_{i} q_{k}|u|^{2} \\
& +2 a_{i k} q_{i}\left(\left|D_{k} u\right|^{2}-f_{k} u D_{k} \bar{u}-f_{k} \bar{u} D_{k} u+f_{k}^{2}|u|^{2}\right) d x \\
& =\int_{D} \sum_{i, k}-\left[a_{i k} f_{i}^{2} q_{k}+f_{i} D_{i}\left(a_{i k} q_{k}\right)+D_{i}\left(a_{i k} f_{i} q_{k}\right)+D_{i}^{2}\left(a_{i k} q_{k}\right)\right]|u|^{2} \\
& +\left[D_{k}^{2}\left(a_{i k} q_{i}\right)-a_{i k} q_{i} q_{k}+2 D_{k}\left(a_{i k} q_{i} f_{k}\right)+2 a_{i k} q_{i} f_{k}^{2}\right]|u|^{2} \\
& -2 a_{i k} q_{i}\left|D_{k} u\right|^{2}+2 a_{i k} q_{i}\left|D_{k} u\right|^{2} d x
\end{aligned}
$$




$$
\begin{aligned}
& +\sum_{\dot{D}} \sum_{i, k}\left[a_{i k} q_{i} D_{k}|u|^{2}-D_{k}\left(a_{i k} q_{i}\right)|u|^{2}-2 a_{i k} q_{i} f_{k}|u|^{2}\right] \nu_{k} d s \\
= & \int_{D} \sum_{i, k}\left[a_{i k} q_{i}\left(f_{k}^{2}-q_{k}\right)-f_{i} D_{i}\left(a_{i k} q_{k}\right)+D_{i}\left(a_{i k} f_{i} q_{k}\right)\right]|u|^{2} d x \\
& +\int_{\dot{D}}[\cdots] d s \\
= & \int_{D} \sum_{i, k}\left[-a_{i k} q_{i} D_{k} f_{k}-f_{k} D_{k}\left(a_{i k} q_{i}\right)+D_{k}\left(a_{i k} f_{k} q_{i}\right)\right]|u|^{2} d x \\
& +\int_{\dot{D}}[\cdots] d s \\
= & \int_{\dot{D}}\left[a_{i k} q_{i} D_{k}|u|^{2}-D_{k}\left(a_{i k} q_{i}\right)|u|^{2}-2 a_{i k} q_{i} f_{k}|u|^{2}\right] \nu_{k} d s,
\end{aligned}
$$

which was to be shown.

(1) We will reserve the notation $q(x)$ for a positive function of of the form $q(x)=\sum_{i, k}\left(f_{i}+D_{i}\right)^{2} a_{i k} q_{k}$.

Corollary 1. Suppose that $D$ is any open set. If $a_{i k}(x)$ is uniformly bounded in $D$, then

$$
\int_{D} \sum_{i, k} a_{i k} D_{i}^{2} u D_{k}^{2} \bar{u}-q|u|^{2} d x \geqq 0,
$$

for every $u \in \stackrel{\circ}{H}_{q}(D)$ and equality holds if and only if $D_{i}^{2} u=q_{i} u$ and $D_{i} u=f_{i} u$ almost everywhere, for each $i$.

Proof. It is easy to obtain the inequality for functions in $C_{0}^{\infty}(D)$ by integrating around a sphere containing the support of $u$. The result for $u \in \stackrel{\circ}{H}_{q}(D)$ can then be obtained by showing that

$$
\int_{D} a_{i k} D_{i}^{2} u_{m} D_{k}^{2} \bar{u}_{m} d x \stackrel{m}{\longrightarrow} \int_{D} a_{i k} D_{i}^{2} u D_{k}^{2} \bar{u} d x
$$

which follows easily from Cauchy's inequality.

COROLlaRY 2. If $\left(a_{i k}\right)$ is only positive semidefinite, the same inequality holds but the conditions for equality are not necessarily the same. If $a_{i k}=1$, the conditions are

$$
\sum_{i}\left(D_{i}^{2} u-q_{i} u\right)=0 \quad \text { and } \quad D_{i} u=f_{i} u
$$

ExAMPLE 1. Corollary 2 can be used to obtain inequalities whenever a solution $u_{1}$ of a plate problem

$$
\left.\begin{array}{rlr}
\Delta \Delta u-p u=0 & \text { in } D \\
u=0 \\
\Delta u=0
\end{array}\right\} \quad \text { on } \dot{D}
$$


is known. Here $\Delta u=\sum_{k} D_{k}^{2} u$ and $\Delta \Delta u=\sum_{i, k} D_{i}^{2} D_{k}^{2} u$. Suppose that $u_{1}>0$ in $D$ and let $f_{k}=\left(D_{k} u_{1}\right) / u_{1}$. We must show that

$$
\sum_{k}\left(f_{k}+D_{k}\right) f_{k}=\sum_{k} \frac{D_{k}^{2} u_{1}}{u_{1}} \leqq 0 .
$$

For this it suffices to show that $\sum_{k} D_{k}^{2} u_{1} \leqq 0$. If $\sum_{i} D_{i}^{2} v=p u_{1} \geqq 0$ and $v=0$ on $\dot{D}$, then $v \leqq 0$ by the maximum principle. Set $v=$ $\sum_{k} D_{k}^{2} u_{1}$, then $v$ satisfies the problem and hence $\sum_{k} D_{k}^{2} u_{1} \leqq 0$ in $D$. Calculate

$$
\sum_{i, k}\left(f_{i}+D_{i}\right)^{2}\left(f_{k}+D_{k}\right) f_{k}=\sum_{i, k} \frac{D_{i}^{2} D_{k}^{2} u_{1}}{u_{1}}=p
$$

So

$$
\int_{D} \sum_{i, k} D_{i}^{2} u D_{k}^{2} \bar{u}-p|u|^{2} d x \geqq 0, \quad \text { for } \quad u \in C_{0}^{\infty}(D) .
$$

In particular, for $p=\lambda q$, where $\lambda$ is the first eigenvalue of the plate problem and $u_{1}$ is the corresponding eigenfunction, the inequality becomes Rayleigh's characterization of the first eigenvalue. In this case, the conditions for equality become $u=k u_{1}$.

EXAMPle 2. Suppose $n \geqq 5$, then

$$
\int_{D} \sum_{i, k} D_{i}^{2} u D_{k}^{2} \bar{u}-\frac{n^{2}(n-4)^{2}}{16}\left(\sum_{i=1}^{n} x_{i}^{2}\right)^{-1}|u|^{2} d x \geqq 0 ，
$$

for every $u \in \stackrel{\circ}{H}_{q}$. To apply Corollary 1 , let $f_{k}=(a / s) x_{k}$, where $s=$ $\sum_{i=1}^{n} x_{i}^{2}$, then

$$
\begin{aligned}
q_{k} & =\frac{a(a-2)}{s^{2}} x_{k}^{2}+\frac{a}{s}, \\
\sum_{k=1}^{n} q_{k} & =\frac{a(a+(n-2))}{s} \leqq 0 \text { if } 2-n \leqq a<0
\end{aligned}
$$

(the other possibility leads to nothing of interest). Calculate,

$$
q=\frac{1}{s^{2}} a(a-2)[a-(4-n)][a-(2-n)] .
$$

Then $q>0$, if $a<0, a-2>0$, and $a \geqq 4-n$. If we choose $a=$ $(4-n) / 2$, then $q$ is maximal and equal to $\left(n^{2}(n-4)^{2}\right) / 16$.

It is unfortunate that the preceding example is only good for dimensions larger than five. The following inequality, though unappealing, does yield an example for every dimension. 
Theorem 2. Let $f_{1}, f_{2}, \cdots, f_{n} \in C^{1}(D)$ and suppose that

$$
\sum_{i, k} D_{i} f_{i}\left|\xi_{k}\right|^{2}+\left(D_{k} f_{i}+D_{i} f_{k}+f_{i} f_{k}\right) \xi_{i} \bar{\xi}_{k} \leqq 0
$$

for every vector $\left(\xi_{1}, \xi_{2}, \cdots, \xi_{n}\right)$. Then

$$
\begin{aligned}
\int_{D} \sum_{i, k} D_{i}^{2} u D_{k}^{2} \bar{u} & -\left[D_{k}^{2} D_{i} f_{i}+3 f_{k} D_{k} D_{i} f_{i}+f_{i} D_{k}^{2} f_{i}\right. \\
& +2 f_{k}^{2} D_{i} f_{i}+4 f_{i} f_{k} D_{k} f_{i}+\left(D_{k} f_{i}\right)^{2}+\left(D_{k} f_{i}\right)\left(D_{i} f_{k}\right) \\
& \left.+\left(D_{k} f_{k}\right)\left(D_{i} f_{i}\right)+f_{i}^{2} f_{k}^{2}\right]|u|^{2} d x \\
\geqq & \int_{\dot{D}} \sum_{i, k}\left[2 \operatorname{Re} D_{i}\left(f_{i} u\right) D_{k} \bar{u}-f_{i}\left|D_{k} u\right|^{2}\right. \\
& -\left(D_{k} D_{i} f_{i}+2 f_{k} D_{i} f_{i}+f_{i} D_{k} f_{i}\right. \\
& \left.\left.+f_{i} D_{i} f_{k}+f_{i}^{2} f_{k}\right)|u|^{2}\right] \nu_{k} d s
\end{aligned}
$$

Proof.

$$
\begin{aligned}
\sum_{i, k}\left[D_{i}^{2} u\right. & \left.-D_{i}\left(f_{i} u\right)\right]\left[D_{k}^{2} \bar{u}-D_{k}\left(f_{k} \bar{u}\right)\right]-D_{i} f_{i}\left|D_{k} u-f_{k} u\right|^{2} \\
& \left.\left.-\left(D_{k} f_{i}+D_{i} f_{k}+f_{i} f_{k}\right)\left(D_{i} u-f_{i} u\right)\right) D_{k} \bar{u}-f_{k} \bar{u}\right) \geqq 0
\end{aligned}
$$

when expanded the first term in (2) contains the following two terms which we integrate by parts:

$$
-D_{i}\left(f_{i} u\right) D_{k}^{2} \bar{u}-D_{i}\left(f_{i} \bar{u}\right) D_{k}^{2} u \quad \text { and } \quad D_{i}\left(f_{i} u\right) D_{k}\left(f_{k} \bar{u}\right) \text {. }
$$

Notice that the order of summation has been changed in the first term.

$$
\begin{aligned}
& -\int_{D} D_{i}\left(f_{i} u\right) D_{k}^{2} \bar{u}+D_{i}\left(f_{i} \bar{u}\right) D_{k}^{2} u d x \\
= & \int_{D} D_{k} D_{i}\left(f_{i} u\right) D_{k} \bar{u}+D_{k} D_{i}\left(f_{i} \bar{u}\right) D_{k} u d x \\
& -\int_{\dot{D}}\left[D_{i}\left(f_{i} u\right) D_{k} \bar{u}+D_{i}\left(f_{i} \bar{u}\right) D_{k} u\right] \nu_{k} d s \\
= & \int_{D}\left(u D_{k} D_{i} f_{i}+D_{i} f_{i} D_{k} u+D_{k} f_{i} D_{i} u+f_{i} D_{k} D_{i} u\right) D_{k} \bar{u} \\
& +\left(\bar{u} D_{k} D_{i} f_{i}+D_{i} f_{i} D_{k} \bar{u}+D_{k} f_{i} D_{i} \bar{u}+f_{i} D_{k} D_{i} \bar{u}\right) D_{k} u \\
& -\int_{\dot{D}}[\cdots] \nu_{k} d s \\
= & \int_{D} D_{k} D_{i} f_{i} D_{k}|u|^{2}+f_{i} D_{i}\left|D_{k} u\right|^{2}+2 D_{i} f_{i}\left|D_{k} u\right|^{2} \\
& +D_{k} f_{i} D_{i} u D_{k} \bar{u}+D_{k} f_{i} D_{i} \bar{u} D_{k} u d x \\
- & \int_{\dot{D}}[\cdots] \nu_{k} d s
\end{aligned}
$$


(3)

$$
\begin{aligned}
= & \int_{D}-\left(D_{k}^{2} D_{i} f_{i}\right)|u|^{2}+\left(D_{i} f_{i}\right)\left|D_{k} u\right|^{2} \\
& +D_{k} f_{i} D_{i} u D_{k} \bar{u}+D_{k} f_{i} D_{i} \bar{u} D_{k} u d x \\
& +\int_{\dot{D}}\left[-2 \operatorname{Re} D_{i}\left(f_{i} u\right) D_{k} \bar{u}+D_{k} D_{i} f_{i}|u|^{2}+f_{i}\left|D_{k} u\right|^{2}\right] \nu_{k} d s
\end{aligned}
$$

and

$$
\begin{aligned}
\int_{D} & \sum_{i, k} D_{i}\left(f_{i} u\right) D_{k}\left(f_{k} \bar{u}\right) d x \\
= & \int_{D} \sum_{i, k}\left(D_{i} f_{i}\right)\left(D_{k} f_{k}\right)|u|^{2}+f_{k}\left(D_{i} f_{i}\right)\left(u D_{k} \bar{u}+\bar{u} D_{k} u\right) \\
& +f_{i} f_{k}\left(D_{i} u\right)\left(D_{k} \bar{u}\right) d x \\
= & \int_{D} \sum_{i, k}\left(D_{i} f_{i}\right)\left(D_{k} f_{k}\right)|u|^{2}-D_{k}\left[f_{k}\left(D_{i} f_{i}\right)\right]|u|^{2}+f_{i} f_{k}\left(D_{i} u\right)\left(D_{k} \bar{u}\right) d x \\
& +\int_{\dot{D}} \sum_{i, k} f_{k}\left(D_{i} f_{i}\right)|u|^{2} \nu_{k} d s \\
(4)= & \int \sum_{i, k}-f_{k}\left(D_{k} D_{i} f_{i}\right)|u|^{2}+f_{i} f_{k}\left(D_{i} u\right)\left(D_{k} \bar{u}\right) d x \\
& +\int_{\dot{D}} \sum_{i, k} f_{k}\left(D_{i} f_{i}\right)|u|^{2} \nu_{k} d s .
\end{aligned}
$$

The second term in (2) contains

( 5 )

$$
\begin{aligned}
\int_{D} f_{k} D_{i} & f_{i}\left(u D_{k} \bar{u}+\bar{u} D_{k} u\right) d x \\
= & -\int_{D}\left[\left(D_{k} f_{k}\right)\left(D_{i} f_{i}\right)+f_{k} D_{k} D_{i} f_{i}\right]|u|^{2} d x \\
& +\int_{\bar{D}} f_{k} D_{i} f_{i}|u|^{2} \nu_{k} d s .
\end{aligned}
$$

The third term in (2) contains

$$
\begin{aligned}
\int_{D} \sum_{i, k}\left(D_{k} f_{i}+D_{i} f_{k}+f_{i} f_{k}\right)\left(f_{i} u D_{k} \bar{u}+f_{k} \bar{u} D_{i} u\right) d x \\
=\int_{D} \sum_{i, k} f_{i}\left(D_{k} f_{i}+D_{i} f_{k}+f_{i} f_{k}\right) D_{k}|u|^{2} d x \\
=-\int_{D} \sum_{i, k} D_{k}\left(f_{i} D_{k} f_{i}+f_{i} D_{i} f_{k}+f_{i}^{2} f_{k}\right)|u|^{2} d x \\
\quad+\int_{\dot{D}} \sum_{i, k} f_{i}\left(D_{k} f_{i}+D_{i} f_{k}+f_{i} f_{k}\right)|u|^{2} \nu_{k} d s .
\end{aligned}
$$

Expanding (2) and making use of (3), (4), (5) and (6), one can obtain the advertised result.

Corollary. Suppose that $f_{i}$ is a function of $x_{i}$ alone. Then 


$$
\begin{aligned}
& \int_{D} \sum_{i, k} D_{i}^{2} u D_{k}^{2} \bar{u}-\sum_{i}\left[D_{i}^{3} f_{i}+4 f_{i} D_{i}^{2} f_{i}+4 f_{i}^{2} D_{i} f_{i}+2\left(D_{i} f_{i}\right)^{2}\right]|u|^{2} \\
&-\sum_{i, k}\left[2 f_{k}^{2} D_{i} f_{i}+\left(D_{k} f_{k}\right)\left(D_{i} f_{i}\right)+f_{i}^{2} f_{i}^{2}\right]|u|^{2} d x \\
& \geqq 0, \text { for every } u \in \stackrel{\circ}{H}_{q}
\end{aligned}
$$

where $q$ is the coefficient of $|u|^{2}$.

EXAmple 3. Let $f_{i}=a / x_{i}$. Then

$$
\begin{aligned}
\sum_{i, k} D_{i} f_{i}\left|\xi_{k}\right|^{2}+ & \left(D_{k} f_{i}+D_{i} f_{k}+f_{i} f_{k}\right) \xi_{i} \bar{\xi}_{k} \\
= & \sum_{i, k}-\frac{a}{x_{i}^{2}}\left|\xi_{k}\right|^{2}+\frac{a^{2}}{x_{i} x_{k}} \xi_{i} \bar{\xi}_{k}+\sum_{i}-\frac{2 a}{x_{i}^{2}}\left|\xi_{i}\right|^{2} \\
& =a^{2} \sum_{i, k} \frac{\xi_{i} \bar{\xi}_{k}}{x_{i} x_{k}}-a \sum_{i} \frac{1}{x_{i}^{2}} \sum_{i}\left|\xi_{i}\right|^{2}-2 a \sum_{i} \frac{\left|\xi_{i}\right|^{2}}{x_{i}^{2}} \\
& \leqq\left(a^{2}-a\right) \sum_{i}\left|\xi_{i}\right|^{2} \sum_{i} \frac{1}{x_{i}^{2}}-2 a \sum \frac{\left|\xi_{i}\right|^{2}}{x_{i}^{2}}
\end{aligned}
$$

Let $a=1+\varepsilon, \varepsilon>0$. The right side will be negative when

$$
\varepsilon \sum_{i}\left|\xi_{i}\right|^{2} \sum_{i} \frac{1}{x_{i}^{2}} \leqq 2 \sum_{i} \frac{\left|\xi_{i}\right|^{2}}{x_{i}^{2}}
$$

Take $\lambda_{i}=\left(\left|\xi_{i}\right|^{2}\right) /\left(\sum_{i}\left|\xi_{i}\right|^{2}\right)$, then $\sum_{i} \lambda_{i}=1$ and the inequality becomes

$$
\frac{\varepsilon}{2} \sum_{i} \frac{1}{x_{i}^{2}} \leqq \sum_{i} \lambda_{i} \frac{1}{x_{i}^{2}}
$$

It is always possible to choose an $\varepsilon$ so that this inequality holds provided $D$ is bounded and bounded away from the origin. For let $0<m \leqq x_{i}^{2} \leqq M$, then

$$
\sum_{i} \lambda_{i} \frac{1}{x_{i}^{2}} \geqq \frac{1}{M} \text { and } \quad \sum_{i} \frac{1}{x_{i}^{2}} \leqq \frac{n}{m} .
$$

Take $\varepsilon / 2 \leqq(m / n M)$ and the inequality holds.

Let us compute $q$ using the formula in the corollary.

$$
\begin{aligned}
q & =\sum_{i} \frac{-6 a+8 a^{2}-4 a^{3}+2 a^{2}}{x_{i}^{4}}+\sum_{i, k} \frac{-2 a^{3}+a^{2}+a^{4}}{x_{i}^{2} x_{k}^{2}} \\
& =\sum_{i} \frac{\left(-4 a^{3}+10 a^{2}-6 a\right)}{x_{i}^{4}}+a^{2}(a-1)^{2} \sum_{i, k} \frac{1}{x_{i}^{2} x_{k}^{2}} \\
& =\left(a^{4}-6 a^{3}+11 a^{2}-6 a\right) \sum_{i} \frac{1}{x_{i}^{4}}+a^{2}(a-1)^{2} \sum_{i \neq k} \frac{1}{x_{i}^{2} x_{k}^{2}} \\
& =a(a-1)(a-2)(a-3) \sum_{i} \frac{1}{x_{i}^{4}}+a^{2}(a-1)^{2} \sum_{i \neq k} \frac{1}{x_{i}^{2} x_{k}^{2}} .
\end{aligned}
$$


Taking $a=1+\varepsilon$

$$
q=\varepsilon(1+\varepsilon)(1-\varepsilon)(2-\varepsilon) \sum_{i} \frac{1}{x_{i}^{4}}+\varepsilon^{2}(1+\varepsilon)^{2} \sum_{i \neq k} \frac{1}{x_{i}^{2} x_{k}^{2}}
$$

which is positive for $\varepsilon<1$ or for $\varepsilon>2$.

THEOREM 3. A fourth order existence theorem.

Let $q(x)$ be a function of the special form (1) and let $p(x)$ be a continuously differentiable function such that $0<p(x) \leqq(1-\varepsilon) q(x)$, where $\varepsilon>0$ and fixed. Let $\int_{D} q^{-1}|f|^{2} d x<\infty, g \in H_{q}$ and let $A u=$ $\sum_{i, k} D_{i}^{2}\left(a_{i k} D_{k}^{2} u\right)-p u$ be a uniformly elliptic operator. That is, $a_{i k}$ is positive definite and there exist positive constants $M$ and $\lambda$ such that

$$
\left|a_{i k}(x)\right| \leqq M \quad \text { and } \quad \lambda \sum_{i}\left|\xi_{i}\right|^{2} \leqq \sum_{i, k} a_{i k}(x) \xi_{i} \bar{\xi}_{k},
$$

for any $\left(\xi_{1}, \xi_{2}, \cdots, \xi_{n}\right)$ and all $x$ in $D$. Then the Dirichlet problem

$$
\left.\begin{array}{rlrl}
A u & =f & & \text { in } D \\
u & =g & \\
\sum_{i} D_{\imath}^{?} u & =\sum_{i} D_{i}^{?} g
\end{array}\right\} \text { on } \dot{D}
$$

has a unique weak solution.

Proof. We must show that there is a function $u \in H_{q}$ such that $u-g \in \stackrel{\circ}{H}_{q}$ and $(u, A \varphi)=(f, \varphi)$, for every $\varphi$ in $C_{0}^{\infty}$. Set $u_{0}=u-g$ and consider the equivalent problem of finding $u_{0} \in \dot{H}_{q}$ such that $\left(u_{0}, A \varphi\right)=(f, \varphi)-(g, A \varphi)$. Let

$$
\begin{aligned}
B(u, v) & =\int_{D} \sum_{i, k} a_{i k} D_{i}^{2} u D_{k}^{2} \bar{v}-p u \bar{v} d x \\
& =\int_{D} \sum_{i, k} u D_{i}^{2}\left(a_{i k} D_{k}^{2} \bar{v}-p u \bar{v} d x\right. \\
& =(u, A v), \text { for } u, v \in C_{0}^{\infty} .
\end{aligned}
$$

We will show that there exist $c_{1}, c_{2}>0$ such that

$$
\begin{aligned}
|B(u, v)| & \leqq C_{1}\|u\|_{q}\|v\|_{q} \text { and } B(u, u) \geqq C_{2}\|u\|_{q}^{2} . \\
B(u, u) & =\int_{D} \sum_{i, k} a_{i k} D_{\imath} u D_{k} \bar{u}-p|u|^{2} d x \\
& \geqq \int_{D} \sum_{i, k} a_{i k} D_{i} u D_{k} \bar{u}-q|u|^{2} d x+\varepsilon \int_{D} q|u|^{2} d x .
\end{aligned}
$$

By Corollary 1, both integrals are positive and hence 


$$
\begin{aligned}
\left(1+\frac{2}{\varepsilon}\right) B(u, u) & \geqq \int_{D} \sum a_{i k} D_{i} u D_{k} \bar{u}+q|u|^{2} d x \\
& \geqq \int_{D} \lambda \sum_{i}\left|D_{i} u\right|^{2}+q|u|^{2} d x \\
& \geqq \text { const }\|u\|_{q}^{2}
\end{aligned}
$$

The positivity of $B(u, u)$ implies that $|B(u, v)|^{2} \leqq B(u, u) \cdot B(v, v)$ so that we need only show that $B(u, u) \leqq$ const $\|u\|_{q}^{2}$.

$$
\begin{aligned}
B(u, u) & \leqq M \int_{D} \sum_{\imath, k}\left|D_{i} u D_{k} \bar{u}\right|+p|u|^{2} d x \\
& \leqq \int_{D} \sum_{i, k} \frac{1}{2}\left(\left|D_{i} u\right|^{2}+\left|D_{k} u\right|^{2}\right)+p|u|^{2} d x \\
& \leqq M n \int_{D} \sum_{i}\left|D_{i} u\right|^{2}+p|u|^{2} d x=M n\|u\|_{q}^{2}
\end{aligned}
$$

Now extend $B(u, v)$ to all of $\stackrel{\circ}{H}_{q}$ by continuity. We can now apply the Lax-Milgram Theorem which guarantees that any bounded linear functional $F(\varphi)$ on $\stackrel{\circ}{H}_{q}$ can be represented as $\overline{B\left(u_{0}, \varphi\right)}$ for some $u_{0} \in \stackrel{\circ}{H}_{q}$. Take $F(\varphi)=\overline{(f, \varphi)-B(g, \varphi)}$. Then

$$
\begin{aligned}
|F \varphi| \leqq & \left(\int_{D} q^{-1}|f|^{2} d x\right)^{1 / 2}\left(\int_{D} q|\varphi|^{2} d x\right)^{1 / 2} \\
& +c_{1}\|\varphi\|_{q}\|g\|_{q} \leqq \text { const }\|\varphi\|_{q}
\end{aligned}
$$

So $B\left(u_{0}, \varphi\right)=(f, \varphi)-B(g, \varphi)$ as was to be shown. To obtain the uniqueness result, let $A u=0, u \in \stackrel{\circ}{H}_{q}$, then

$$
0=(u, A u)=B(u, u) \geqq C_{2}\|u\|_{q}^{2} . \quad \therefore u=0 \text { a.e. }
$$

\section{REFERENCE}

1. James Calvert, An integral inequality with applications to the Dirichlet problem, Pacific J. Math. 22 (1967).

Received June 8, 1967.

UNIVERStTy of CALIFornia, DAVIS 



\section{PACIFIC JOURNAL OF MATHEMATICS}

EDITORS

H. ROYDEN

Stanford University

Stanford, California

R. R. Phelps

University of Washington

Seattle, Washington 98105
J. DugundJI

Department of Mathematics

University of Southern California

Los Angeles, California 90007

\section{RICHARD ARENS}

University of California

Los Angeles, California 90024

\section{ASSOCIATE EDITORS}
E. F. BeCKENBACH
B. H. NeUmanN
F. WOLF
K. YOSIDA

\section{SUPPORTING INSTITUTIONS}

UNIVERSITY OF BRITISH COLUMBIA CALIFORNIA INSTITUTE OF TECHNOLOGY UNIVERSITY OF CALIFORNIA MONTANA STATE UNIVERSITY UNIVERSITY OF NEVADA NEW MEXICO STATE UNIVERSITY OREGON STATE UNIVERSITY UNIVERSITY OF OREGON OSAKA UNIVERSITY UNIVERSITY OF SOUTHERN CALIFORNIA
STANFORD UNIVERSITY UNIVERSITY OF TOKYO UNIVERSITY OF UTAH WASHINGTON STATE UNIVERSITY UNIVERSITY OF WASHINGTON

AMERICAN MATHEMATICAL SOCIETY CHEVRON RESEARCH CORPORATION TRW SYSTEMS NAVAL WEAPONS CENTER 


\section{Pacific Journal of Mathematics \\ Vol. 27, No. $1 \quad$ January, 1968}

Willard Ellis Baxter, On rings with proper involution ............... 1

Donald John Charles Bures, Tensor products of $W^{*}$-algebras........... 13

James Calvert, Integral inequalities involving second order derivatives . . . . 39

Edward Dewey Davis, Further remarks on ideals of the principal class.... 49

Le Baron O. Ferguson, Uniform approximation by polynomials with integral

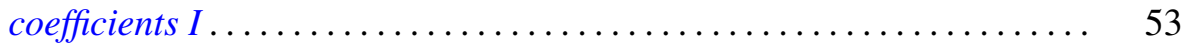

Francis James Flanigan, Algebraic geography: Varieties of structure

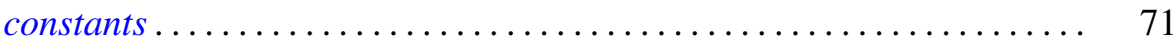

Denis Ragan Floyd, On QF -1 algebras ..................... 81

David Scott Geiger, Closed systems of functions and predicates ......... 95

Delma Joseph Hebert, Jr. and Howard E. Lacey, On supports of regular Borel measures ................................... 101

Martin Edward Price, On the variation of the Bernstein polynomials of a function of unbounded variation ........................ 119

Louise Arakelian Raphael, On a characterization of infinite complex matrices mapping the space of analytic sequences into itself........ 123

Louis Jackson Ratliff, Jr., A characterization of analytically unramified

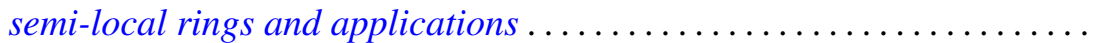

S. A. E. Sherif, A Tauberian relation between the Borel and the Lototsky transforms of series ................................ 145

Robert C. Sine, Geometric theory of a single Markov operator .......... 155

Armond E. Spencer, Maximal nonnormal chains in finite groups......... 167

Li Pi Su, Algebraic properties of certain rings of continuous functions .... 175

G. P. Szegô, A theorem of Rolle's type in $E^{n}$ for functions of the class $C^{1} \ldots 193$

Giovanni Viglino, A co-topological application to minimal spaces ........ 197

B. R. Wenner, Dimension on boundaries of $\varepsilon$-spheres ............... 201 